\title{
Effects of kaolin particle films on the life span of an orb-weaver spider
}

\author{
Jacinto Benhadi-Marín a, b , José Alberto Pereira a, Sónia A.P. Santos a, * \\ ${ }^{a}$ Mountain Research Centre (CIMO), School of Agriculture, Polytechnic Institute of Bragança, Campus of Santa Apolónia, PO Box 1172, $5301-855$ Bragança, \\ Portugal \\ ${ }^{\mathrm{b}}$ Department of Life Sciences, University of Coimbra, 3004-517 Coimbra, Portugal
}

\section{H I G H L I G H T S}

- Effects of kaolin sprays on the life span of Araniella cucurbitina were tested.

- Different exposure routes (surface, spider, prey and spider \& prey) were studied.

- Life span was significantly reduced when kaolin was sprayed on surface.

- Spray of kaolin simultaneously on spider \& prey also affected life span.

- Multiple kaolin sprays may have negative effects on A. cucurbitina populations.

\section{A R T I C L E I N F O}

\section{Article history:}

Received 14 March 2015

Received in revised form

10 September 2015

Accepted 18 September 2015

Available online $\mathrm{xxx}$

\section{Keywords:}

Araniella curcubitina

Survival

Exposure to kaolin

Alternative pesticide

Weight

\begin{abstract}
A B S T R A C T
Araniella cucurbitina (Araneae: Araneidae) is a widespread orb-weaver spider commonly found in agroecosystems. Mineral particle films such as kaolin, due to their protective or anti-feeding action, can represent an alternative to pesticides, especially in organic farming systems, but little is known about its effects on A. cucurbitina. Therefore, we tested the effect of kaolin sprays on the life span of A. cucurbitina under laboratory conditions. Four treatments were tested encompassing different exposure routes. Thus, kaolin sprays were applied on (i) the surface, (ii) the prey (fly), (iii) the spider and (iv) both spider \& prey. A control group was tested with water in each treatment. Results showed that sprays of kaolin significantly affected the survival of $A$. curcubitina when applications were done on the surface and on both spider \& prey registering a reduction of $48 \%$ and $56 \%$, respectively. Spiders in control obtained higher probability of reaching alive at the end of the assay than those treated with kaolin. Differences observed can be explained by the feeding behavior of the species and may depend on the consumption of the web by the spider and the ratio spider/fly for body size.
\end{abstract}

(c) 2015 Elsevier Ltd. All rights reserved.

\section{Introduction}

Pest management strategies commonly involve the use of agrochemicals in order to maintain or improve crop yield for feeding the world population (Arias-Estévez et al., 2008). However, numerous negative effects resulting from the use of synthetic pesticides include risks for non-target organisms and persistence in the environment (Geiger et al., 2010; Sánchez-Bayo et al., 2013; Santos et al., 2007).

Technology developed on mineral particle films can represent

\footnotetext{
* Corresponding author. Present address: Barreiro School of Technology, Polytechnic Institute of Setúbal, Rua Américo da Silva Marinho, 2839-001 Lavradio, Portugal.

E-mail address: saps@ipb.pt (S.A.P. Santos).
}

an alternative to some pesticides used in the control of pests (Glenn et al., 1999; Glenn and Puterka, 2005). In this context, kaolin is a white aluminosilicate mineral clay, chemically inert over a wide $\mathrm{pH}$ range that has been widely used in a variety of industrial applications, including paints, cosmetics, pharmaceuticals and agriculture (Glenn et al., 1999; Glenn and Puterka, 2005; Knight et al., 2000).

The interest for this natural substance is reflected in the number of works covering different crops such as pear (Puterka et al., 2000; Daniel et al., 2005), apple (Knight et al., 2001; Friedrich et al., 2003), olive (Pascual et al., 2010), walnut and almond (Rosati et al., 2006), citrus (Hall et al., 2007), wine grape (Glenn et al., 2010), pecan (Cottrell et al., 2002), cotton (Showler, 2003; Silva and Ramalho, 2012), tomatoes (Kahn and Damicone, 2008) and cabbage (Alavo and Abagli, 2011). In general, those and other studies showed kaolin as an effective substance in reducing the population of 
several groups of pests, such as Hemiptera (Daniel et al., 2005; Alavo and Abagli, 2011; Martinou et al., 2014), Lepidoptera (Showler, 2003; Sackett et al., 2007), Diptera (Mazor and Erez, 2004; Pascual et al., 2010) and Coleoptera (Silva and Ramalho, 2012). Kaolin acts as a repellent or barrier for pests, affecting the recognition and attractiveness of host plants (Showler, 2002).

The effect on beneficial arthropods has been less studied and side effects were reported for Coccinellidae and parasitoids such as Aphelinidae and Pteromalidae by Pascual et al. (2010) and species such as Anthocoris nemoralis (F.) (Hemiptera: Anthocoridae), Chilocorus nigritus (F.) (Coleoptera: Coccinellidae), Chelonus inanitus (L.) (Hymenoptera: Braconidae) and Scutellysta cyanea Motschulsky (Hymenoptera: Pteromalidae) by Bengochea et al. (2013). Concerning spiders, Sackett et al. (2007), Markó et al. (2010) and Pascual et al. (2010) observed a reduction of density of spiders in crop fields. Spiders are generalist predators with important predatory action in agroecosystems and ability to reduce the populations of various insect pests (Marc et al., 1999; Nyffeler and Sunderland, 2003; Riechert and Lockley, 1984).

Spiders can be exposed to kaolin directly during its application by forming a film of particles on the body and/or by ingesting particles when feeding on sprayed prey or surfaces. Effects of these different exposure routes on spiders have never been studied. Thus, the objective of this work was to assess the effect of kaolin solution applications on the life span of Araniella cucurbitina (Clerck) (Araneae: Araneidae) under laboratory conditions and considering different exposure routes. A. curcubitina was selected in this study as test organism because it is an orb-web building spider species, commonly found in several agro-forest ecosystems throughout Europe and Asia where it is considered as being an effective biological control agent of several pests such as Diptera, Lepidoptera and winged aphids (Marc and Canard, 1997; Marc et al., 1999; Isaia et al., 2006; Cardoso et al., 2008; Pascual et al., 2014).

\section{Material and methods}

\subsection{Spider origin and rearing}

Spiderlings of A. cucurbitina were originally captured by hand from their webs on shrubs near Rabal (Bragança, northeast of Portugal) in early May 2013. They were transported individually in plastic tubes $(6.0 \mathrm{~cm}$ height $\times 1.0 \mathrm{~cm}$ in diameter) to the laboratory, transferred to plastic Petri dishes $(5.5 \mathrm{~cm}$ in diameter and $1.8 \mathrm{~cm}$ height) and placed in a climate chamber at $21 \pm 1{ }^{\circ} \mathrm{C}, 70 \pm 5 \%$ relative humidity and a photoperiod of 16:8 (L:D) h. Every two days, two drops of water were spread, with a pipette, on a double filter paper strip $(1.0 \times 2.0 \mathrm{~cm})$ placed on the bottom of the Petri dish to maintain humidity. Spiderlings were fed twice a week with three vinegar flies, Drosophila melanogaster Meigen (Diptera: Drosophilidae), obtained from a laboratory culture maintained at the School of Agriculture of the Polytechnic Institute of Bragança (ESA) (Bragança, Portugal) since 1999. After reaching maturity, the identification of the species was confirmed according to Roberts (1985); adults of $A$. cucurbitina were then individually placed in glass Petri dishes $(8.0 \mathrm{~cm}$ in diameter and $1.4 \mathrm{~cm}$ height) and five flies were provided twice a week.

Four adult males and females were randomly selected to mate and each male was transferred to a Petri dish with the female. These four couples were observed in order to ensure that mating occurred. After mating, each male was taken and placed again into its Petri dish. Every other day, gravid females were provided with one individual of the Mediterranean fruit fly, Ceratitis capitata (Wiedemann) (Diptera: Tephritidae), obtained from a laboratory culture maintained at the ESA since 2012. Egg sacs laid by females were carefully removed from the web using curved scissors and forceps, placed in the middle of two cotton layers and transferred to plastic Petri dishes $(5.5 \mathrm{~cm}$ in diameter and $1.8 \mathrm{~cm}$ height). They were maintained on strips of moistened filter paper placed on the bottom of the Petri dish till spiderlings had left the egg sac. Spiders emerged from the egg sac in the second instar (hatching and the first molting occurs inside it). Strips of filter paper were moistened every week with two drops of water. Then, spiderlings were randomly allocated in clusters with five spiders. Each cluster was placed in a plastic Petri dish (5.5 cm in diameter and $1.8 \mathrm{~cm}$ height) and provided ad libitum with $D$. melanogaster till the occurrence of the following molting and third instar spiders were then used in the assays. The third instar can be differentiated from the second since the color of the spiderling becomes temporarily lighter after molting and body size increases significantly.

\subsection{Substance tested}

Kaolin (BAS 24000 F, SURROUND ${ }^{\circledR}-95 \%$ ) was the substance tested in the assays. A 3\% kaolin solution of the commercial product was prepared in water. Every week, kaolin solution was sprayed 10 times, using a sprayer $(100 \mathrm{~mL})$, from a distance of $30 \mathrm{~cm}$ to each Petri dish according to the treatment.

\subsection{Survival and dry body weight}

After reaching the third instar, each spider was placed individually in a glass Petri dish ( $8 \mathrm{~cm}$ in diameter and $1.4 \mathrm{~cm}$ height) and fed with $D$. melanogaster (four flies were provided once a week during the first three weeks and eight flies thereafter). Spiders were tested with one of the following treatments: (1) surface - where only the inner walls of the Petri dish were sprayed with kaolin solution, (2) prey - where only flies were sprayed, (3) spider where only the spider was sprayed and (4) spider \& prey - where both spider and flies were sprayed. Control groups, for each treatment, received the same quantity of water. Twenty five individuals were used in each treatment, except in the assays prey/kaolin and spider/control where 24 individuals were used. In the first treatment (Surface), the spider was removed from the Petri dish with a small paintbrush, kaolin solution was applied both on the bottom and top of the Petri dish and the spider was put back immediately into it. In the second treatment (Prey), flies were left in a freezer at $5{ }^{\circ} \mathrm{C}$ for $10 \mathrm{~min}$ to reduce activity and then sprayed and placed immediately into the Petri dish. In the third treatment (Spider), spiders were removed from the Petri dishes with the paintbrush and kaolin solution was applied all around the spider when it was suspended by its silk filament. The same methods were used in the fourth treatment (Spider \& Prey). Assays were maintained for 42 days and survival was checked on a daily basis. This time period was chosen since, according to previous experiments, the fitness of A. cucurbitina remains high, decreasing after the third month under laboratory conditions. Dead spiders were removed from the Petri dish, dried in an oven at $60{ }^{\circ} \mathrm{C}$ for $24 \mathrm{~h}$ and dry body weight was registered.

\subsection{Data analysis}

Statistical analyses were performed using $\mathrm{R}$ software ( $\mathrm{R}$ Core Team, 2014). The effects of kaolin application on A. cucurbitina for each modality were investigated in four steps:

(1) Survival curves were generated for each treatment using Kaplan-Meier estimates and statistical differences between curves were assessed with a log-rank test statistic using the Surv, survfit and survdiff functions from the "survival" 
package. Survival curves were used to calculate the decrease of the probability of survival at the end of the experiment.

(2) Statistical differences between dry weight registered in kaolin and control were assessed in each treatment using the non-parametric Wilcoxon rank-sum test that estimates the probability that a randomly chosen subject from the first group (control) has a higher weight than a randomly chosen subject from the second group (kaolin); Dry weight was divided by the number of days that each spider lived at the end of the experiment to obtain the corrected body weight and the median and the first and third quartiles were calculated and presented as a measure of the central tendencies.

(3) The probability $\left(\pi_{i}\right)$ of each spider to reach alive at the end of the assay was calculated by developing generalized linear models (GLM) for binary data. For each treatment the kaolin application (coded as factor: control and kaolin), the corrected body weight and the interaction between the two terms were used as explanatory variables and the status of each spider at the end of the experiment as the binary independent variable $(0=$ dead; $1=$ alive $)$. Then the full model (Eq. (1)) is given by:

$$
\begin{aligned}
& Y_{i} \sim B\left(1, \pi_{i}\right) \\
& \begin{array}{l}
E\left(Y_{i}\right)=\pi_{i} \text { and } \operatorname{var}\left(Y_{i}\right)=\pi_{i} \times\left(1-\pi_{i}\right) \\
\quad \operatorname{logit}\left(\pi_{i}\right)=\alpha+\beta_{1} \times \text { Treatment }_{i}+\beta_{2} \times \text { Weight }_{i} \\
\quad+\beta_{3} \times \text { Treatment }_{i} * \text { Weight }_{i}
\end{array}
\end{aligned}
$$

There was no need to check for overdispersion within the models since the range of the response variable $\left(\pi_{\mathrm{i}}\right)$ can only vary between 0 and 1 . The interaction term was not significant in any case, thus a model selection was applied by nesting the two models (with and without the interaction term) within modalities and the AIC criterion was followed according to Zuur et al. (2009) in order to select the optimal model. Then, for all modalities the optimal model (Eq. (2)) remained:

$\operatorname{logit}\left(\pi_{i}\right)=\alpha+\beta_{1} \times$ Treatment $_{i}+\beta_{2} \times$ Weight $_{i}$

The overall data distribution was explored by plotting together for each spider (i) the raw dry weight, (ii) the number of days survived and (iii) the probability of survival calculated through the models (Eq. (2)) into a three-dimensional scatter plot using the function scatterplot3d from the "scatterplot3d" package and;

(4) Finally, the models (Eq. (2)) were used to obtain the theoretical response of each group of spiders in terms of probability of surviving in each treatment.

\section{Results}

Spider survival was significantly influenced by kaolin application in Surface and Spider \& Prey treatments (Fig. 1A and D, Table 1). On the contrary, when only the Prey or the Spider were sprayed with kaolin, no differences were observed between the treatment and control individuals (Fig. 1B and C, Table 1). In all cases, there was a decrease in the survival function after 12 days from the beginning of the experiment (Fig. 1). The highest decrease in the survival function was observed in the Spider \& Prey treatment (Fig. 1D) whereas the Prey treatment showed the stablest curve (Fig. 1B). Regarding the reduction of survival registered (difference between kaolin and control) at the end of the experiment, kaolin caused a reduction of $56 \%$ when compared with control in the
Spider \& Prey treatment followed by Surface with 48\%, Prey with $14 \%$ and Spider treatment with $2 \%$.

Considering the corrected spider body weight (calculated as the dry body weight at death/number of days survived), control reached higher values than kaolin in all treatments although no significant differences were observed between them. The Surface treatment registered the lowest difference between control and kaolin, with a median [quartiles] of $0.022[0.014,0.038] \mathrm{mg} /$ day and $0.022[0.009,0.037] \mathrm{mg} /$ day respectively $(\mathrm{W}=351.5 ; \mathrm{P}=0.455)$ while the highest difference was registered for Spider \& Prey treatment with $0.021[0.013,0.037] \mathrm{mg} /$ day for control and 0.015 $[0.009,0.026] \mathrm{mg} /$ day for kaolin respectively $(\mathrm{W}=402 ; \mathrm{P}=0.084)$. Spider treatment registered median [quartiles] of 0.025 [0.006, $0.053] \mathrm{mg} / \mathrm{day}$ and $0.021[0.010,0.028] \mathrm{mg} / \mathrm{day}(\mathrm{W}=348$; $\mathrm{P}=0.497)$ and Prey $0.021[0.008,0.047] \mathrm{mg} / \mathrm{day}$ and $0.021[0.011$, $0.043] \mathrm{mg} /$ day respectively for control and kaolin $(\mathrm{W}=305.5$; $\mathrm{P}=0.899$ ).

Regarding the whole dataset (Fig. 2), kaolin applications resulted in general in two different data distributions, in the case of Surface and Spider \& Prey treatments, control was separated from kaolin due to a high probability of spider survival in the former and a low probability of spider survival treated with kaolin (Fig. 2A and D) whereas data points in Prey (Fig. 2B) and Spider (Fig. 2C) treatments, were more overlapped along the y-axis. The ratio for the probability of spiders to reach alive at the end of the experiment, comparing control and kaolin was 4.50 and 3.00 for Spider \& Prey and Surface treatments respectively, whereas in the case of Prey and Spider treatments, the ratios were 1.33 and 1.08 . Heavier spiders were related to a lower probability of surviving. This effect was especially evident at the end of the assay (day 42) (Fig. 2). When modeling the probability of each group of spiders reaching alive at the end of the assay, the fitted curves for control remained above the curves for kaolin application in all cases (Fig. 3) and the probability of surviving was significantly higher in the control of Surface and Spider \& Prey treatments (Table 2).

\section{Discussion}

The effects of kaolin application have been mainly studied at the ecosystem level where the susceptibility of spiders can be influenced by their foraging mode. For instance, in apple orchards, the abundance of wanderer spiders (e.g. Salticidae, Philodromidae and Thomisidae families) decreased after kaolin sprays while orb-waver spiders (e.g. Araneidae, Dictinidae and Theridiidae families) were less affected or not affected at all (Sackett et al., 2007; Markó et al., 2010). In olive orchards, Pascual et al. (2010) observed a decrease of the abundance of Philodromidae as well as of A. cucurbitina after three years of study. Kaolin particles can interfere with the hunting ability of wandered spiders that seemed to be more vulnerable to sprays than orb-weaver spiders, because of their direct contact with the surface (Pekár, 1999; Sackett et al., 2007; Markó et al., 2010).

Although, in the field, the risks of kaolin treatment to spiders may depend on their foraging mode, our study suggests that the exposure route can also be relevant for spider's survival. A. cucurbitina is a medium size spider (body length male: $3.5-4.5 \mathrm{~mm}$, body length female: $4.5-9.5 \mathrm{~mm}$ ) that spends most of the time on its web such as other species of the orb-weavers group (Foelix, 1996). Thus, it can be expected to find a low or non-effect of kaolin when only the surface (i.e. Petri dish) was sprayed. However, both survival curves and models revealed a significant negative effect of kaolin on spiders in Surface treatment when compared with control. This effect can be explained by the ecology of orbweaving spiders since usually they rebuild their webs in order to recycle the amino acids contained in the silk (Blackledge et al., 

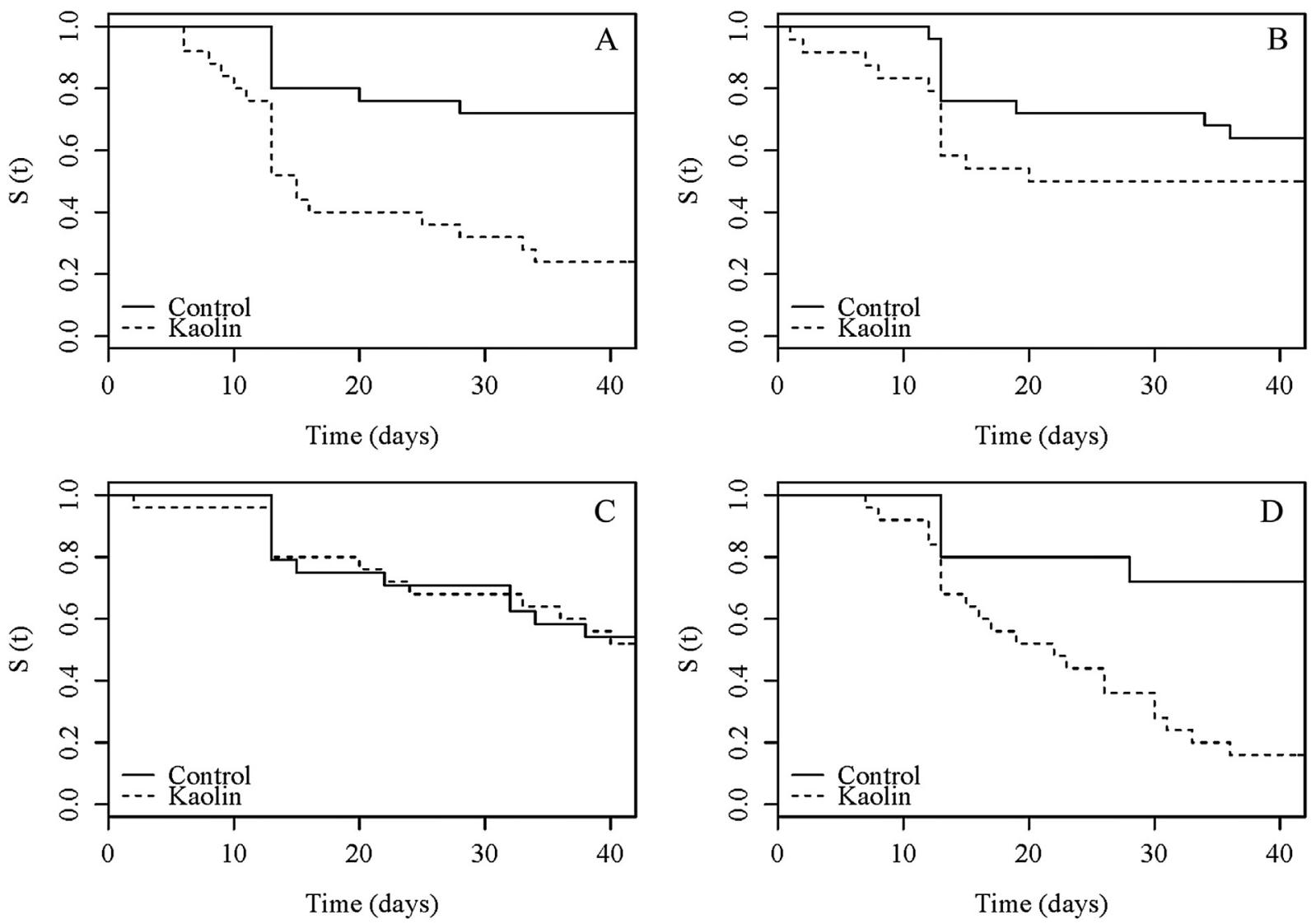

Fig. 1. Survival curves for each treatment over 42 days of experimental assay. S(t) is the estimated survival function. A: Surface; B: Prey; C: Spider and D: Spider \& Prey.

Table 1

Log-rank test statistics for comparisons of survival curves (control vs. kaolin application) obtained for each treatment.

\begin{tabular}{|c|c|c|c|c|c|c|c|c|}
\hline Treatment & Assay & $\mathrm{N}$ & Observed & Expected & $(O-E)^{\wedge} 2 / E$ & $\chi^{2}$ & $\mathrm{df}$ & $\mathrm{P}$ \\
\hline \multirow[t]{2}{*}{ Surface } & Control & 25 & 7 & 15.40 & 4.54 & 12.60 & 1 & $<0.0125$ \\
\hline & Kaolin & 25 & 19 & 10.60 & 6.55 & & & \\
\hline \multirow[t]{2}{*}{ Prey } & Control & 25 & 9 & 11.74 & 0.64 & 1.62 & 1 & 0.204 \\
\hline & Kaolin & 24 & 12 & 9.26 & 0.81 & & & \\
\hline \multirow[t]{2}{*}{ Spider } & Control & 24 & 11 & 11.30 & $<0.01$ & 0.01 & 1 & 0.905 \\
\hline & Kaolin & 25 & 12 & 11.70 & $<0.01$ & & & \\
\hline \multirow[t]{2}{*}{ Spider \& Prey } & Control & 25 & 7 & 16.70 & 5.62 & 15.30 & 1 & $<0.0125$ \\
\hline & Kaolin & 25 & 21 & 11.30 & 8.23 & & & \\
\hline
\end{tabular}

2011; Wilder, 2011). Firstly, when kaolin was sprayed on the inner walls of the Petri dish, the spider web also received kaolin particles and, after each application, spiders probably needed to repair or rebuild their webs and this may mean that they consumed a significant amount of silk covered with kaolin, and secondly according to Townley et al. (2006) and Blackledge et al. (2011), viscid orbweaving spiders such as $A$. cucurbitina recycle their webs in order to exploit some components of the glue droplets. Probably during our experiment, kaolin particles deposited on the top of the dish constantly fell on the web, being held by glue drops, and thus increasing the amount of kaolin intake by spiders when recycling their webs.

According to Hall et al. (2007) body size can be an important factor when assessing the effects of particle films on mortality among species. Considering body size of spider and fly, the former is considerably bigger than the latter, and this ratio spider/fly increases through the assay. Thus, when only the flies were treated, the intake of kaolin by the spider was not enough to cause lethal effects when eating the small sized flies. In addition, the extra-oral digestion performed by spiders (Cohen, 1995) probably played an important role since this feeding type has the advantage of separating the non-digestible potential food (Wilder, 2011) and the hairlike formations located on spiders mouthparts can also filter small particles (Foelix, 1996) such as those of kaolin.

When only the spider was sprayed with kaolin, the main exposure route is through body contact and the amount of kaolin sprayed was not probably enough to cause any effect on the spider life span. Kaolin forms a film of particles that can accumulate around the articulations limiting the mobility of arthropods (Porcel et al., 2011). This is particularly relevant in the case of hunting arthropods, however, for A. cucurbitina, since it is not a running spider this does not seem to be relevant. Other potential effects of kaolin particles are respiratory complications caused by obstruction of the book lung and pulmonary spiracle which are located on the ventral side of the abdomen. In this study, all sides of the body of A. cucurbitina were sprayed and no effect was observed showing 
A

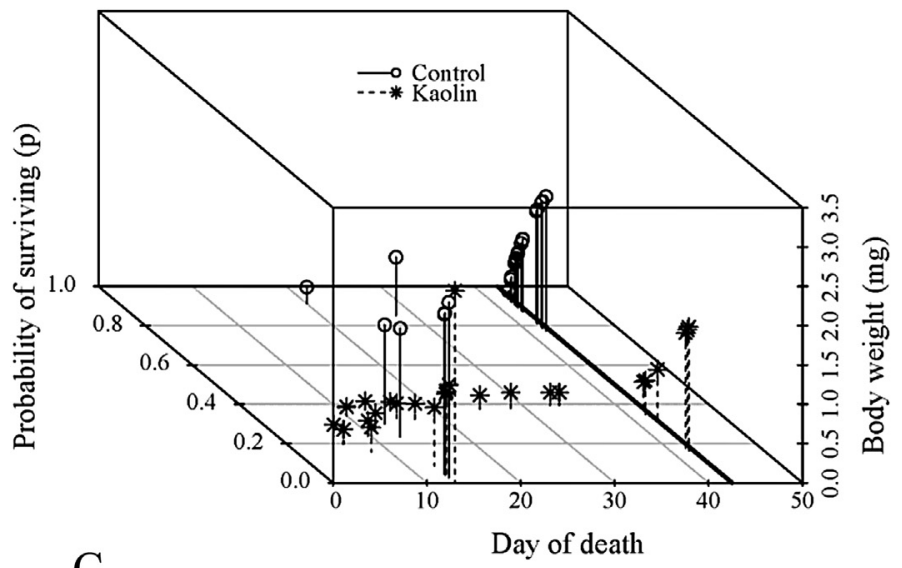

$\mathrm{C}$

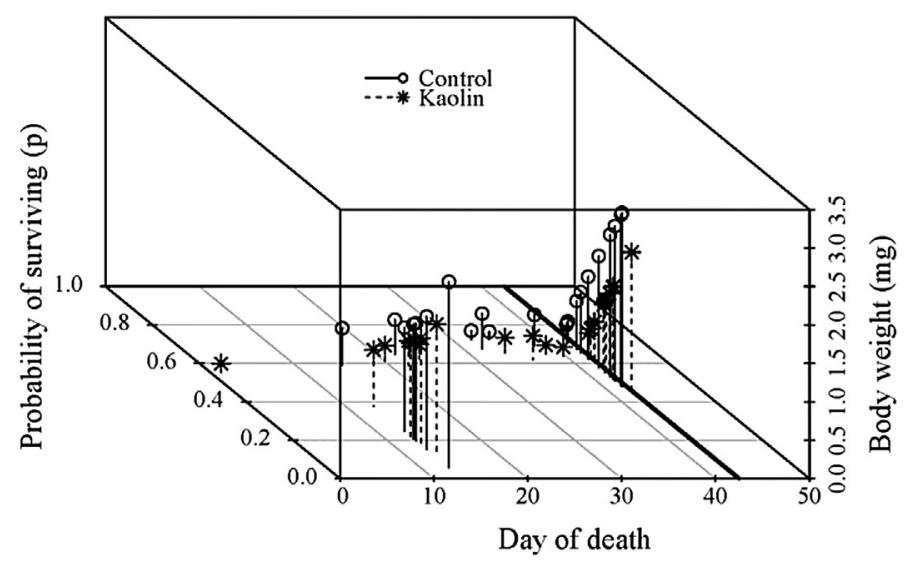

B
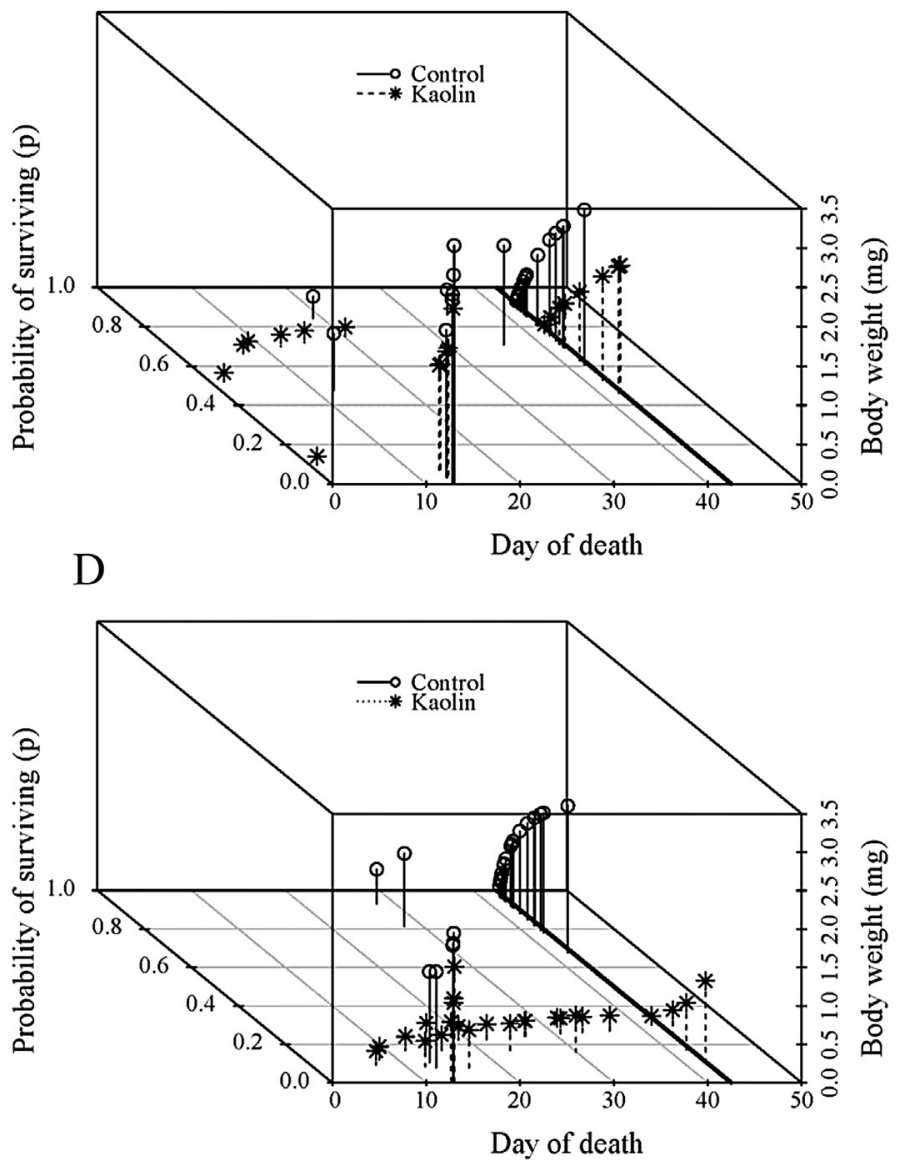

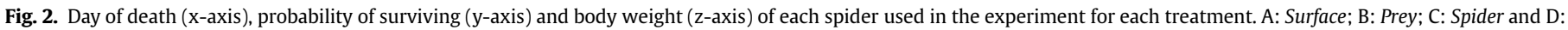
Spider \& Prey. Each point represents a spider. Thick black continuous lines represent the end of the experiment at day 42.

high tolerance to particles; besides, in field, potential effects would have been prevented if spiders had have its ventral side in contact with a surface (e.g. a leaf), and thus protected, at the time of the spray. Moreover, the molting process must remove kaolin particles adhered to the body surface re-establishing the initial situation (Porcel et al., 2011).

No differences were observed between control and kaolin for both the Prey and Spider treatments (Fig. 3) however our results suggest a possible synergism when exposure to the substance has multiple routes. Namely, for the Spider \& Prey treatment, kaolin had a significant negative effect on the spider's survival (Fig. 3). This result can be explained by the spider's dry body weight. In this treatment, the spiders showed the lowest dry body weight among the whole experiment and this parameter is usually highly collinear with body size (Sage, 1982). Thus, since the number and size of flies eaten by each spider was the same in all treatments, the ratio spider/fly in terms of body size decreased resulting in a higher proportion of kaolin intake by the spider when eating a fly, given that the amount of kaolin sprayed to the flies was the same that in the Prey treatment. In addition, smaller spiders may have experienced higher levels of starvation and, according to Foelix (1996) and Wilder (2011), this fact may cause a change in the spider feeding behavior from sucking to a masticating strategy in an attempt to obtain a greater nutrient profit and thus the amount of kaolin ingested could have increased causing a potential congestion of the digestive tract.
The models indicate that lighter spiders had higher probability of surviving after kaolin sprays than heavier spiders. This fact is probably reflecting that differences in the probability of surviving (according to the body weight) are due to the feeding behavior instead of the spider body development. The pattern observed on the models slopes suggests that the number of flies consumed per unit time may have contributed to these differences. Thus, taking into account that the number of flies eaten by each spider at the end of each week was the same and that each fly can live for a week into the Petri dish (J. Benhadi-Marin, personal observation), spiders that registered lower final body weight probably consumed less flies per unit time along each week and probably had a constant intake of kaolin keeping it below a lethal threshold. On the contrary, spiders that ate the flies more quickly may have grown faster but also the amount of ingested kaolin increased in the same proportion with consequences for survival. Since body weight could be related with the life span of the individual, the effect of this variable should be considered with caution and the model can be used mainly for comparisons between control and kaolin application, despite the occurrence of different drivers causing mortality. Comparing with other insecticides used in integrated or conventional pest management, no similar laboratory studies could be found but two field studies referred spinosad bait sprays as having no negative effects on A. cucurbitina (Pascual et al., 2014) and broad spectrum insecticides (e.g. chlorpyrifos) as causing negative effects on Araniella opistographa (Kulczyński) and A. cucurbitina, but a fast colonization 

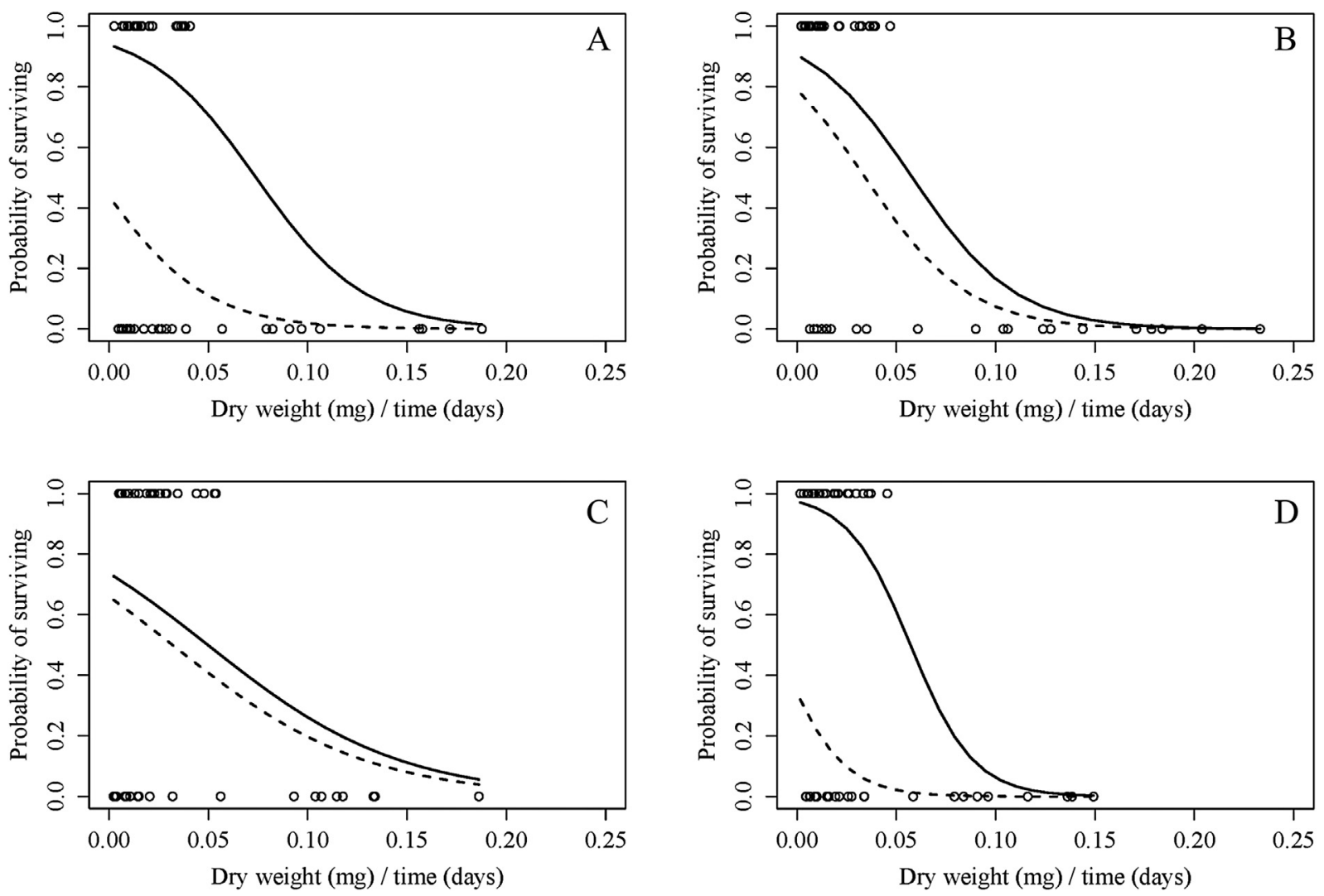

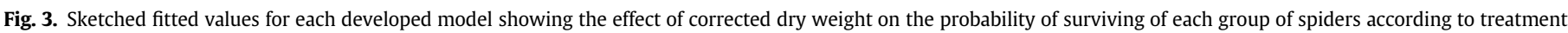
(continuous lines indicate control and dashed lines indicates kaolin application). A: Surface; B: Prey; C: Spider and D: Spider \& Prey.

Table 2

Effect of treatment and dry weight on the probability $\left(\pi_{\mathrm{i}}\right)$ of each spider to reach alive at the end of the assay. For each developed model, results are presented as a deviance table. IV: Independent Variable; LRCSq: likelihood-ratio chi-square test; df: degrees of freedom.

\begin{tabular}{llccc}
\hline Model & IV & LRCSq & df & $P$ \\
\hline Surface & Treatment & 17.24 & 1 & $<0.0125$ \\
& Dry weight & 13.78 & 1 & $<0.0125$ \\
Prey & Treatment & 1.52 & 1 & 0.218 \\
& Dry weight & 22.04 & 1 & $<0.0125$ \\
Spider & Treatment & 0.35 & 1 & 0.553 \\
& Dry weight & 6.64 & 1 & $<0.0125$ \\
Spider \& Prey & Treatment & 27.52 & 1 & $<0.0125$ \\
& Dry weight & 17.55 & 1 & $<0.0125$
\end{tabular}

of apple plots occurred after pesticide treatments restructuring the population levels (Markó et al., 2009).

\section{Conclusions}

Our results suggest that the use of kaolin-based products may have negative effects on $A$. curcubitina populations in particular if multiple sprays are needed to control pests. This information should be taken into consideration in an integrated pest management system in order to minimize lethal effects on spiders by reducing the number of sprays. Kaolin is an attractive alternative to the synthetic pesticides but negative effects on beneficial arthropods may be related to different ways of action and further research is needed in order to uncover the consequences of multiple contaminations. Moreover, these results were obtained in laboratory conditions and exposure to kaolin can be higher than in field, where spiders can find shelters and non-contaminated preys.

\section{Acknowledgments}

This study was financially supported by FEDER Funds throughout Programa Operacional Factores de Competitividade COMPETE and National Funds throughout FCT - Fundação para a Ciência e Tecnologia, within the project EXCL/AGR-PRO/0591/2012: Olive crop protection in sustainable production under global climatic changes: linking ecological infrastructures to ecosystem functions (Grant number: 130390).

\section{References}

Alavo, T.B.C., Abagli, A.Z., 2011. Effect of kaolin particle film formulation against populations of the aphid Lipaphis erysimi Kalt. (Homoptera: Aphididae) in cabbage. Open Entomol. J. 5, 49-53.

Arias-Estévez, M., López-Periago, E., Martínez-Carballo, E., Simal-Gándara, J., Mejuto, J.C., García-Río, L., 2008. The mobility and degradation of pesticides in soils and the pollution of groundwater resources. Agric. Ecosyst. Environ. 123, 247-260.

Bengochea, P., Amor, F., Saelices, R., Hernando, S., Budia, F., Adán, A., Medina, P., 2013. Kaolin and copper-based products applications: ecotoxicology on four natural enemies. Chemosphere 91, 1189-1195.

Blackledge, T.A., Kuntner, M. Agnarsson, I., 2011. The form and function of spider orb webs: evolution from silk to ecosystems. Adv. Insect Physiol, 41, 175-262.

Cardoso, P., Gaspar, C., Pereira, L.C., Silva, I., Henriques, S.S., Silva, R.R., Sousa, P., 2008. Assessing spider species richness and composition in Mediterranean cork oak forests. Acta Oecol. 33, 114-127.

Cohen, A.C., 1995. Extra-oral digestion in predaceous terrestrial arthropoda. Ann. Rev. Entomol. 40, 85-103.

Cottrell, T.E., Wood, B.W., Reilly, C.C., 2002. Particle film affects black pecan aphid (Homoptera: Aphididae) on pecan. J. Econ. Entomol. 95, 782-788.

Daniel, C., Pfammatter, W., Kehrli, P., Wyss, E., 2005. Processed kaolin as an alternative insecticide against the European pear sucker, Cacopsylla pyri (L.). J. Appl. 
Entomol. 129, 363-367.

Foelix, R.F., 1996. Biology of Spiders. Oxford University Press, New York, Oxford, p. 330.

Friedrich, H., Delate, K., Domoto, P., Nonnecke, G., Wilson, L., 2003. Effect of organic pest management practices on apple productivity and apple food safety. Biol. Agric. Hortic. 21, 1-14.

Geiger, F., Bengtsson, J., Berendse, F., Weisser, W.W., Emmerson, M., Morales, M.B., Ceryngier, P., Liira, J., Tscharntke, T., Winqvist, C., Eggers, S., Bommarco, R., Part, T., Bretagnolle, V., Plantegenest, M., Clement, L.W., Dennis, C., Palmer, C., Oñate, J.J., Guerrero, I., Hawro, V., Aavik, T., Thies, C., Flohre, A., Hänke, S., Fischer, C., Goedhart, P.W., Inchausti, P., 2010. Persistent negative effects of pesticides on biodiversity and biological control potential on European farmland. Basic Appl. Ecol. 11, 97-105.

Glenn, D.M., Cooley, N., Walker, R., Clingeleffer, P., Shellie, K., 2010. Impact of kaolin particle film and water deficit on wine grape water use efficiency and plant water relations. Hortscience 45, 1178-1187.

Glenn, D.M., Outerka, G., Vanderzwet, T., Byers, R., Feldhake, C., 1999. Hydrophobic particle films: a new paradigm for suppression of arthropod pests and plant diseases. I. Econ. Entomol. 92, 759-771.

Glenn, D.M., Puterka, G.J., 2005. Particle films: a new technology for agriculture. In: Janick, J. (Ed.), Horticultural Reviews, vol. 31. John Wiley \& Sons Inc., Oxford, pp. 1-44.

Hall, D.G., Lapointe, S.L., Wenninger, E.J., 2007. Effects of a particle film on biology and behavior of Diaphorina citri (Hemiptera: Psyllidae) and its infestations in citrus. J. Econ. Entomol. 100, 847-854.

Isaia, M., Bona, F., Badino, G., 2006. Influence of landscape diversity and agricultural practices on spiders assemblage in Italian vineyards of Langa Astigiana (Northwest Italy). Environ. Entomol. 35, 297-307.

Kahn, B.A., Damicone, J.P., 2008. Kaolin particle film product applications before harvest begins may not improve marketable yields of fresh tomatoes. HortTechnology 18, 144-147.

Knight, A.L., Unruh, T.R., Christianson, B.A., Puterka, G.J., Glenn, D.M., 2000. Effects of a kaolin-based particle film on oblique banded leafroller (Lepidoptera: Tortricidae). J. Econ. Entomol. 93, 744-749.

Knight, A.L., Christianson, B.A., Unruh, T.R., 2001. Impacts of seasonal kaolin particle films on apple pest management. Can. Entomol. 133, 413-428.

Marc, P., Canard, A., 1997. Maintaining spider biodiversity in agroecosystems as a tool in pest control. Agric. Ecosyst. Environ. 62, 229-235.

Marc, P., Canard, A., Ysnel, F., 1999. Spiders (Araneae) useful for pest limitation and bioindication. Agric. Ecosyst. Environ. 74, 229-273.

Markó, V., Keresztes, B., Fountain, M.T., Cross, J.V., 2009. Prey availability, pesticides and the abundance of orchard spider communities. Biol. Control 48, 115-124.

Markó, V., Bogya, S., Kondorosy, E., Blommers, L.H.M., 2010. Side effects of kaolin particle films on apple orchard bug, beetle and spider communities. Int. J. Pest Manag. 56, 189-199.

Martinou, A.F., Seraphides, N., Stavrinides, M.C., 2014. Lethal and behavioral effects of pesticides on the insect predator Macrolophus pygmaeus. Chemosphere 96, $167-173$.

Mazor, M., Erez, A., 2004. Processed kaolin protects fruits from Mediterranean fruit fly infestations. Crop Prot. 23, 47-51.

Nyffeler, M., Sunderland, K.D., 2003. Composition, abundance and pest control potential of spider communities in agroecosystems: a comparison of European and US studies. Agric. Ecosyst. Environ. 95, 579-612.

Pascual, S., Cobos, G., Seris, E., González-Núñez, M., 2010. Effects of processed kaolin on pests and non-target arthropods in a Spanish olive grove. J. Pest Sci. 83, $121-133$.

Pascual, S., Cobos, G., Seris, E., Sánchez-Ramos, I., González-Núñez, M., 2014. Spinosad bait sprays against the olive fruit fly (Bactrocera oleae (Rossi)): effect on the canopy non-target arthropod fauna. Int. J. Pest Manag. 60, 258-268.

Pekár, S., 1999. Foraging mode: a factor affecting the susceptibility of spiders (Araneae) to insecticide applications. Pestic. Sci. 55, 1077-1082.

Porcel, M., Cotes, B., Campos, M., 2011. Biological and behavioral effects of kaolin particle film on larvae and adults of Chrysoperla carnea (Neuroptera: Chrysopidae). Biol. Control 59, 98-105.

Puterka, G., Glenn, D.M., Sekutowsky, D.G., Unruh, T.R., Jones, S.K., 2000. Progress toward liquid formulations of particle films for insect and disease control in pear. Environ. Entomol. 29, 329-339.

R Core Team, 2014. R: a Language and Environment for Statistical Computing. R Foundation for Statistical Computing, Vienna, Austria. Available at: http://www. R-project.org.

Riechert, E.S., Lockley, T., 1984. Spiders as biological control agents. Ann. Rev. Entomol. 29, 299-320.

Roberts, M., 1985. The Spiders of Great Britain and Ireland. Atypidae to Theridosomatidae, vol. 1. Harley Books, Colchester, Essex.

Rosati, A., Metcalf, S.G., Buchner, R.P., Fulton, A.E., Lampinen, B.D., 2006. Physiological effects of kaolin applications in well-irrigated and water-stressed walnut and almond trees. Ann. Bot. 98, 267-275.

Sackett, T.E., Buddle, C.M., Vincent, C., 2007. Effects of kaolin on the composition of generalist predator assemblages and parasitism of Choristoneura rosaceana (Lep., Tortricidae) in apple orchards. J. Appl. Entomol. 131, 478-485.

Sage, R.D., 1982. Wet and dry-weight estimates of insects and spiders based on length. Am. Midl. Nat. 108, 407-411.

Sánchez-Bayo, F., Tennekes, H.A., Goka, K., 2013. Impact of systemic insecticides on organisms and ecosystems. In: Trdan, S. (Ed.), Insecticides - Development of Safer and More Effective Technologies. InTech, Rijeka, Croatia, pp. 367-416.

Santos, S.A.P., Pereira, J.A., Torres, L.M., Nogueira, A.J.A., 2007. Evaluation of the effects, on canopy arthropods, of two agricultural management systems to contro pests in olive groves from north-east of Portugal. Chemosphere 67, 131-139.

Showler, A.T. 2002. Effects of kaolin-based particle film application on boll weevil (Coleoptera: Curculionidae) injury to cotton. I. Econ. Entomol. 95, 754-762.

Showler, A.T., 2003. Effects of kaolin particle film on beet armyworm, Spodoptera exigua (Hübner) (Lepidoptera: Noctuidae), oviposition, larval feeding and development on cotton, Gossypium hirsutum L. Agric. Ecosyst. Environ. 95, 265-271.

Silva, C.A.D., Ramalho, F.S., 2012. Kaolin spraying protects cotton plants against damages by boll weevil Anthonomus grandis Boheman (Coleoptera: Curculionidae). J. Pest Sci. 86, 563-569.

Townley, M.A., Tillinghast, E.K., Neefus, C.D., 2006. Changes in composition of spider orb web sticky droplets with starvation and web removal, and synthsesis of sticky droplet compounds. J. Exp. Biol. 209, 1463-1486.

Wilder, S.M., 2011. Spider nutrition: an integrative perspective. Adv. Insect Physiol. 40, 87-136.

Zuur, A., Ieno, E.N., Walker, N., Saveliev, A.A., Smith, G.M., 2009. Mixed Effects Models and Extensions in Ecology with R. Springer, New York. 